AGH DRILLING, OIL, GAS • Vol. 32 • No. $1 \cdot 2015$

http://dx.doi.org/10.7494/drill.2015.32.1.221

\author{
R.R. Nair*, K.J. Saltveit*, E. Protasova, T. Bilstad*
}

\title{
IMPROVED OIL PRODUCTION BY MEMBRANES
}

\section{INTRODUCTION}

Designer Water is produced by adjusting the ionic composition of injected seawater (SW) thereby modifying wetting properties of reservoirs. By altering the wetting properties of crude oil, brine and rock systems, CBR, the capillary pressure and relative permeability of oil and water is affected resulting in higher oil recovery (Fig. 1). Low to moderate salinity, 6000-28000 ppm, are most suitable, with several advantages compared to alternative IOR methods. Advantages include achieving higher oil recovery with minimal added investment, assuming that a water-flooding infrastructure is already in place. Injection of Designer Water can be performed during the early life cycle of a reservoir. This process is relatively cheap, environmentally friendly and without chemicals [10].

The physical principle of enhanced oil recovery by Designer Water is by altering the wetting properties of a CBR-system, which has positive effects on capillary pressures and relative permeability of oil and water. The physical and chemical mechanisms of the wettability modification process at the rock surface determine the efficiency of oil recovery. For both carbonates and sandstone reservoirs the oil recovered by injecting original formation water in equilibrium with the CBR-system, is less than for injection of water with other compositions [3]. In addition to wettability alterations, compaction or compression of the rock by injected seawater is also an important mechanism for oil recovery.

Oil recovery is increased considerably from both carbonate and sandstone reservoirs by injecting Designer Water which is specific low salinity seawater (Fig. 1). The concentration of $\mathrm{NaCl}$ in normal seawater is much larger than the concentration of $\mathrm{Ca}^{2+}, \mathrm{Mg}^{2+}$, and $\mathrm{SO}_{4}{ }^{2-}$. An increase of $\mathrm{Na}^{+}$and $\mathrm{Cl}^{-}$in seawater decreases oil recovery.

* Environmental Engineering, University of Stavanger, 4036, Norway remyarnair_80@yahoo.com, kjerstin.j.s@gmail.com, evgy.pro@gmail.com, torleiv.bilstad@uis.no 
Seawater with low $\mathrm{NaCl}$ and spiked with sulphate at temperatures below $100^{\circ} \mathrm{C}$ seems to be the best composition for Designer Water regarding oil recovery [7]. The oil recovery increased dramatically from 37 to $62 \%$ of oil originally in place, OOIP, by spiking the $\mathrm{NaCl}$ depleted seawater with 4 times sulphate concentration of normal SW.
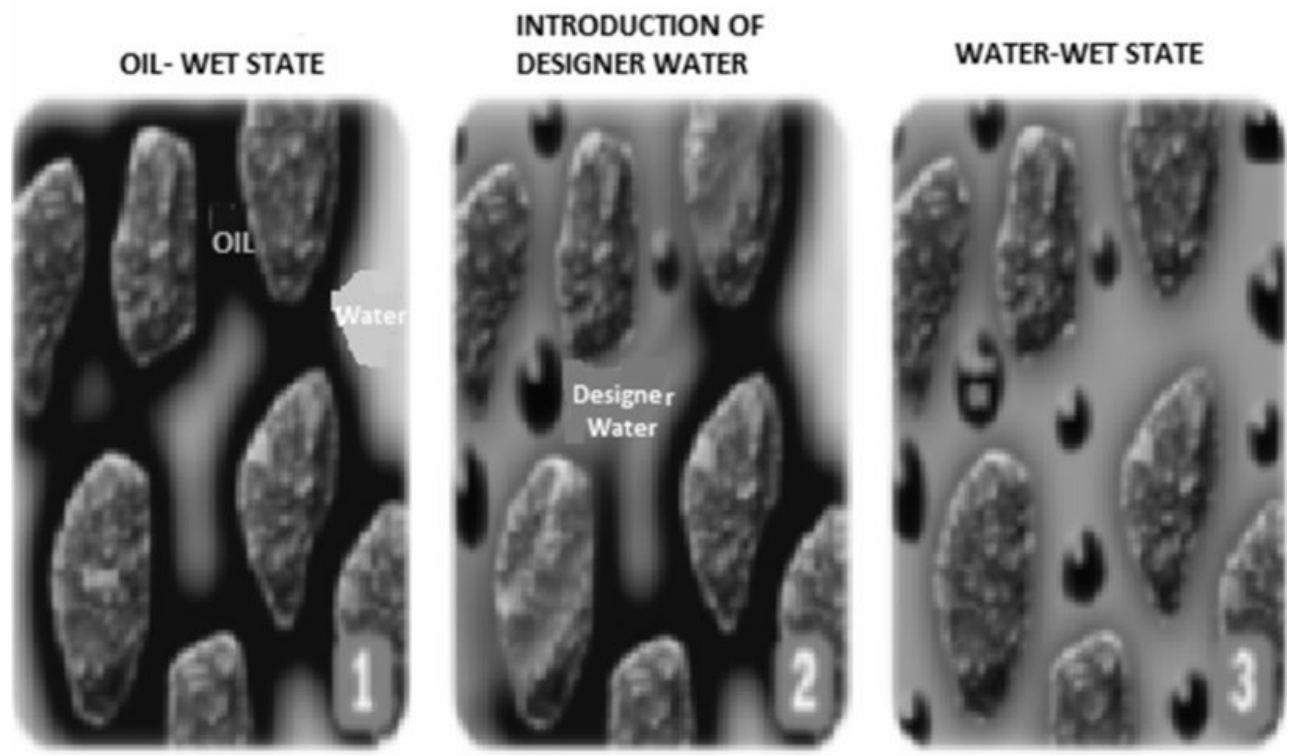

Fig. 1. Effect of designer water into an oil reservoir [15]

\section{SUGGESTED MECHANISMS FOR CHANGING WETTABILITY}

A number of experiments has been performed with seawater flooding in carbonate reservoirs. Wettability alterations were proposed as a key for increasing oil recovery. Schematic for chemical mechanisms for wettability is suggested in Figure 2.

- Injection of brines with high sulphate content coupled with high temperature results in high recovery by spontaneous imbibition [4].

- Sulphate ions adsorb onto the positively charged surface and lower the positive charge.

- $\mathrm{Ca}^{2+}$ close to the rock surface is increased due to reduced electrostatic repulsion and $\mathrm{Ca}^{2+}$ binds to the negatively charged carboxylic groups, releasing oil.

- $\mathrm{SO}_{4}{ }^{2-}$ and $\mathrm{Ca}^{2+}$ at the carbonate surface increase with increasing reservoir temperature.

- $\mathrm{Mg}^{2+}$ displaces $\mathrm{Ca}^{2+}$ from the carbonate rock, indicating that $\mathrm{Mg}^{2+}$ displaces $\mathrm{Ca}^{2+}$ carboxylate complex [3]. 


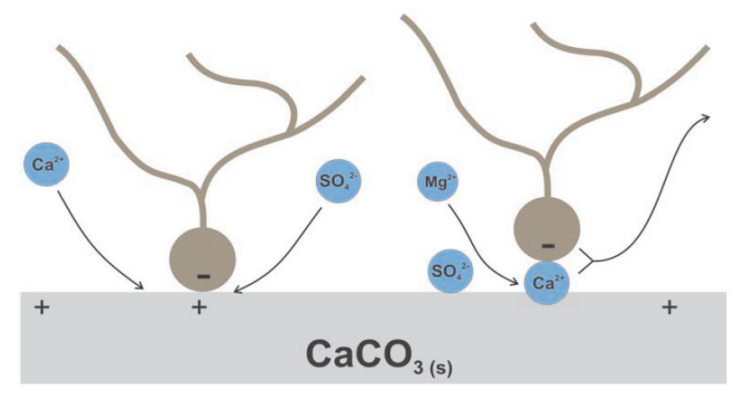

Fig. 2. Model for wettability alteration induced by designer water in carbonate reservoirs [3]

\section{SEPARATION MECHANISMS OF NF MEMBRANES}

The mechanisms of transport and rejection of ions by negatively surface charged NF membranes are due to sorption-surface capillary flow (Donnan exclusion), sieving and solution-diffusion (Fig. 3). With Donnan exclusion the co-ions with the same charge as the membrane are rejected at the membrane surface. Electro-neutrality causes presences of counter ions. Multivalent $\mathrm{SO}_{4}{ }^{2-}$ ions have a higher $\mathrm{NF}$ rejection compared with monovalent anions as charge interactions are larger and co-ions thereby efficiently retained [5]. The Donnan effect is dependent on solute concentrations, valence of co- and counter-ions and surface charge of the membrane [12].

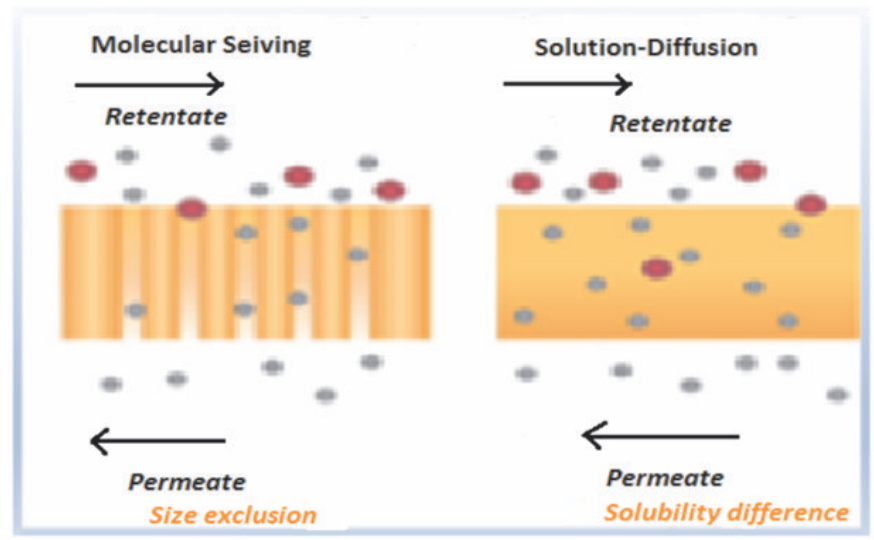

Fig. 3. Molecular sieving and solution diffusion in a membrane [6]

Due to sieving (Stearic hindrance) the membrane rejects solutes with larger molecular weights than the molecular weight cut-off (MWCO) of the membrane. Solutes with lower molecular weights flow as permeate through the membrane [1].

Sieving mechanism causes retention of ions, where hydrated ion radius is compared. Stokes radius (Stoke-Einstein) and hydration energy influence the retention of ions in solution. 
Stokes radius is the radius of a hard sphere that diffuses at the same rate as an equivalent solute and is influenced by solvent water molecules [13]. Rejection of solutes increases with increasing Stokes radius [11] and ions with higher hydration energy are likewise retained.

Hydration energy is the force required to extract the solute from the solvent and transport it into membrane pores. More energy is required to extract ions with higher hydration energy for transport through the pores than ions with lower hydration energy. Thus hydration energy can influence retention [13]. Table 1 provides comparative information according to Stokes radius and hydration energy of the ions in sea water.

Table 1

Stokes radius and hydration energy of ions [9]

\begin{tabular}{|l|c|c|}
\hline \multicolumn{1}{|c|}{ Ion } & Stoke radius $[\mathrm{nm}]$ & Hydration energy $\left[\mathrm{KJ} / \mathrm{mol}^{-1}\right]$ \\
\hline $\mathrm{Na}^{+}$ & 0.184 & 407 \\
\hline $\mathrm{Cl}^{-}$ & 0.121 & 376 \\
\hline $\mathrm{F}^{-}$ & 0.117 & 515 \\
\hline $\mathrm{NO}_{3}{ }^{-}$ & 0.128 & 329 \\
\hline $\mathrm{SO}_{4}^{2-}$ & 0.231 & 1138 \\
\hline $\mathrm{Ca}^{2+}$ & 0.310 & 1584 \\
\hline $\mathrm{Mg}^{2+}$ & 0.341 & 2018 \\
\hline
\end{tabular}

Divalent anions influence the retention of monovalent anions according to Donnan exclusion for solutions of $\mathrm{NaCl}$ and $\mathrm{Na}_{2} \mathrm{SO}_{4}$. By adding $\mathrm{Na}_{2} \mathrm{SO}_{4}$ to a solution of $\mathrm{NaCl}$, the retention of $\mathrm{Cl}^{-}$ions decreases as the concentration of $\mathrm{Na}_{2} \mathrm{SO}_{4}$ increases. The $\mathrm{Na}^{+}$ions are accompanied by negatively charged ions in order to maintain electro neutrality. The negatively charged membrane repels negatively charged ions. However, $\mathrm{Cl}^{-}$ions with the lower potential are forced to permeate preferentially compared with the $\mathrm{SO}_{4}{ }^{2-}$ ions [11].

\section{MEMBRANE PERFORMANCE}

The main membrane parameters are flux, rejection and recovery. Flux is volume per unit membrane area per unit time $\left[\mathrm{L} /\left(\mathrm{m}^{2} \cdot \mathrm{h}\right)\right]$. Rejection characteristics are defined as percentage rejection of solutes. The rejection of ions depends on the salt diffusion coefficient and the solute size. The ion diffusivity follows in order of $\mathrm{Cl}^{-}>\mathrm{Na}^{+}>\mathrm{SO}_{4}{ }^{2-}>\mathrm{Mg}^{2+}>\mathrm{Ca}^{2+}$, while the solute size follows the sequence $\mathrm{Ca}^{2+}>\mathrm{Mg}^{2+}>\mathrm{SO}_{4}{ }^{2-}>\mathrm{Na}^{+}>\mathrm{Cl}^{-}$[2]. $\mathrm{Membrane}^{2}$ re-covery is defined as permeate recovered from feed.

\section{EXPERIMENTAL PROCEDURES}

Two types of membranes were used with normal seawater as feed, Figure 4. Preliminary testing was with NANO-BW-4040 at low pressures. During experiments the feed was 
spiked twice and three times with sulphate. Testing of RO membrane SW 30-2540 was done for dilution purposes. The ions were analysed using ion chromatography.

Filtered seawater was passed through the membrane by varying flow rates of permeate. Retentate was constant at $120 \mathrm{~L} / \mathrm{h}$ throughout the experiments. Permeate flow rates varied from $45 \mathrm{~L} / \mathrm{h}$ to $145 \mathrm{~L} / \mathrm{h}$. Pressure was in the range of 3 to 12 bar.

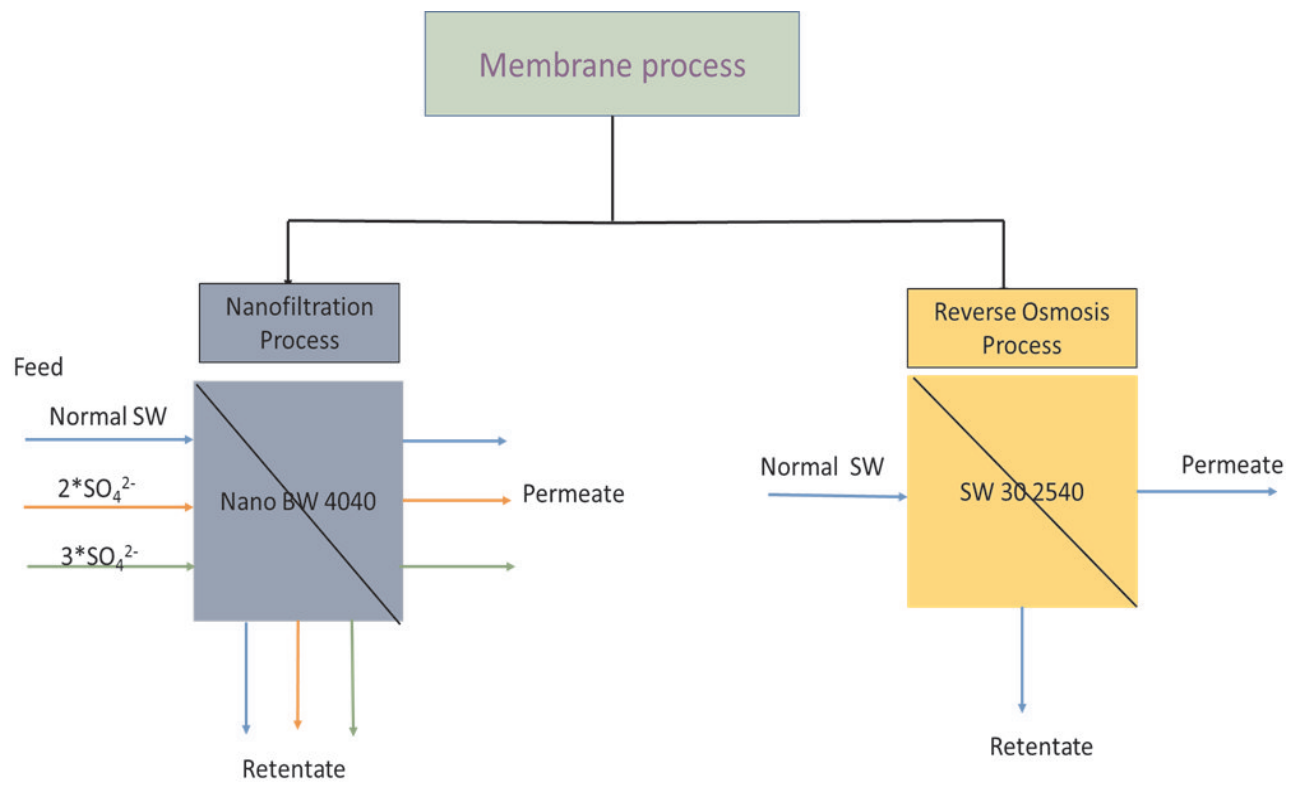

Fig. 4. Experimental membrane set-up

\section{EXPERIMENTAL RESULTS}

Membrane flux, rejections and recoveries at different flow rates were measured and compared.

1. Changes in conductivity, salinity, TDS and flow rates are shown in Table 2.

2. Flux dependence on pressure is calculated as shown in Figure 5.

3. Ion concentrations (rejections) analyzed by chromatography are listed in Table 3 .

4. Figure 6 shows ion concentrations for different pressures and recovery rates.

5. Spiking with sulphate influences separation of ions shown in Tables 4 and 5.

6. The effect of sulphate spiking on flux at 8 bar is shown in Figure 7, where flux decreases as the concentration of $\mathrm{SO}_{4}{ }^{2-}$ in the feed increases.

7. Decrease of flux indicates resistance; i.e., membrane pore size reduction, and change in physical property of solution (density and viscosity).

8. Difference in rejection of sulphate and chloride ions is plotted in Figure 8.

9. TDS of retentate with normal seawater as feed, twice and thrice spiked with sulphate, is plotted in Figure 9. 


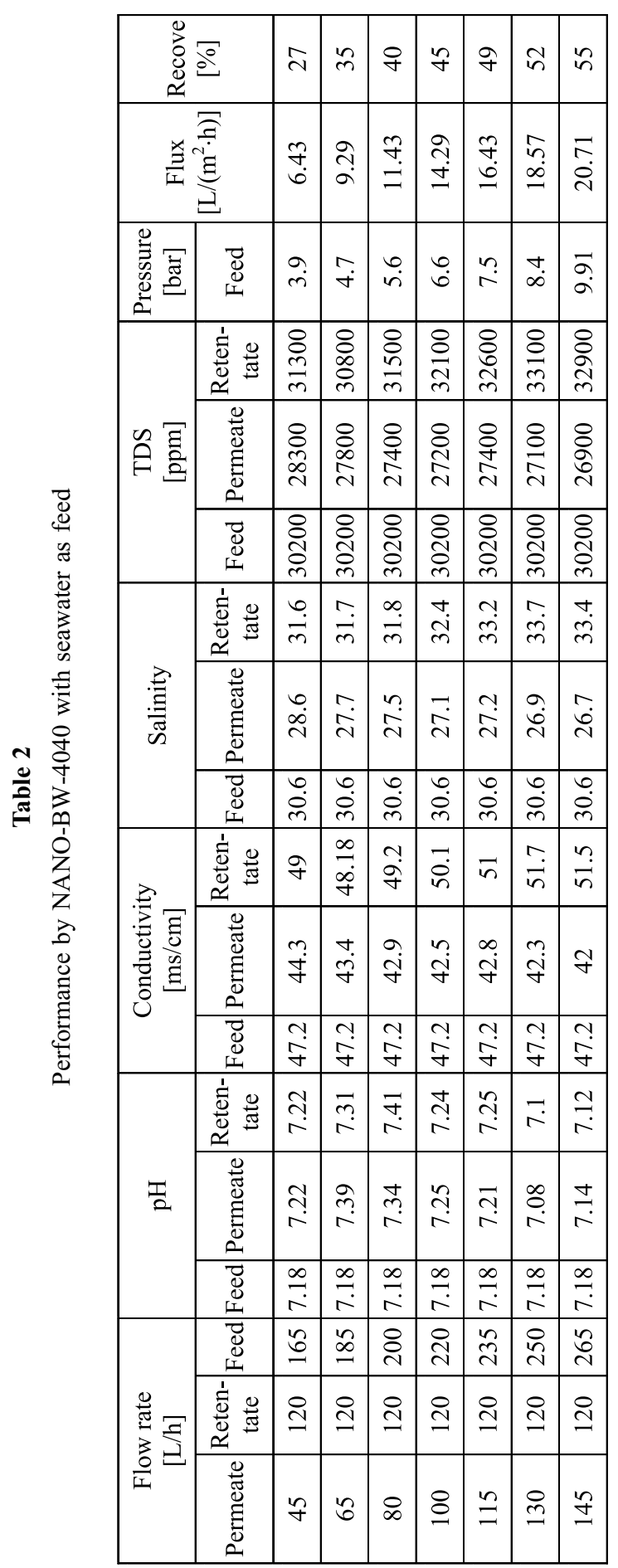




\section{DISCUSSION}

Flux increases linearly with increasing operating pressure according to Figure 5. The resistance to flow through the NF membrane is low compared to a tighter RO membrane.

Salt rejection increases gradually with increasing pressure, explained by an increase in water flux with increasing pressure through the membrane. The higher pressure helps to overcome the hydration energy listed in Table 1. Pressure makes the ions break the bonding with the solvent and move towards the pores of the NF membrane. Hence, the retention of ions increases as solvent permeates; higher flux and higher recovery. Dependence of rejection rate with pressure is proportional for all ions except $\mathrm{SO}_{4}{ }^{2-}$ (Tab. 3).

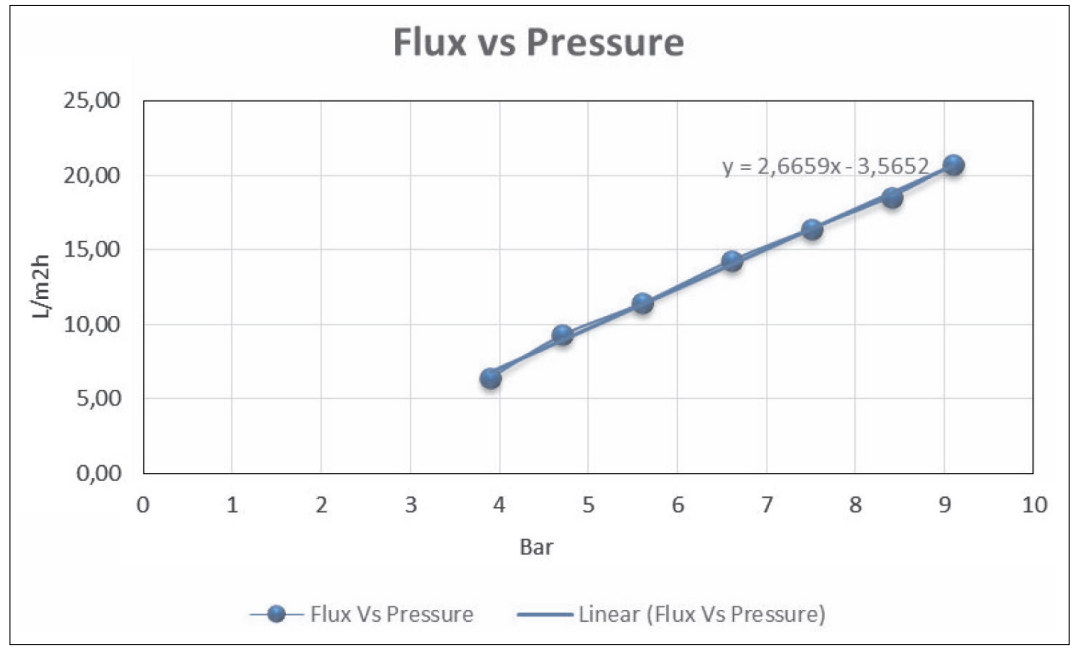

Fig. 5. Flux and pressure with normal seawater as feed to NANO-BW-4040

Table 3

Pressure and rejection by NANO-BW-4040 Separation

\begin{tabular}{|c|c|c|c|c|c|}
\hline \multirow{2}{*}{$\begin{array}{c}\text { Pressure } \\
{[\text { bar] }}\end{array}$} & \multicolumn{5}{|c|}{ Rejection [\%] } \\
\cline { 2 - 6 } & Chloride & Sulphate & Sodium & Magnesium & Calcium \\
\hline 3.9 & 2.7 & 97.7 & 6.9 & 44.5 & 19.7 \\
\hline 4.7 & 3.0 & 96.6 & 5.4 & 49.7 & 14.3 \\
\hline 5.6 & 3.5 & 98.9 & 7.1 & 51.0 & 19.0 \\
\hline 6.6 & 7.1 & 98.9 & 7.1 & 56.6 & 23.6 \\
\hline 7.5 & 6.0 & 98.9 & 7.5 & 54.2 & 19.5 \\
\hline 8.4 & 6.9 & 98.2 & 9.3 & 59.4 & 32.9 \\
\hline 9.1 & 6.9 & 97.8 & 9.0 & 61.1 & 30.7 \\
\hline
\end{tabular}




\section{ION CONCENTRATIONS AND MEMBRANE PROPERTIES}

The results depicted in Figure 6 shows that separation properties of the NF membranes are selective and determined by the co-effect of sieving through the nano-sized pores and Donnan exclusion caused by the surface charge of NF membranes [8].
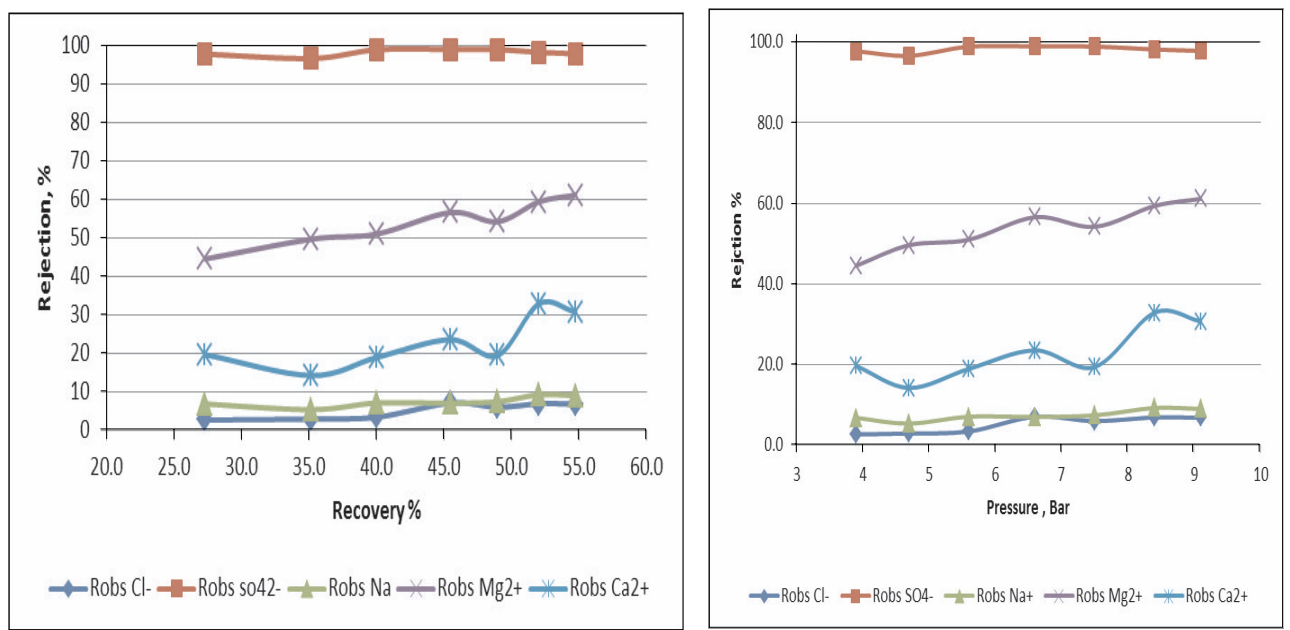

Fig. 6. Pressure, recovery and rejection with NANO-BW-4040

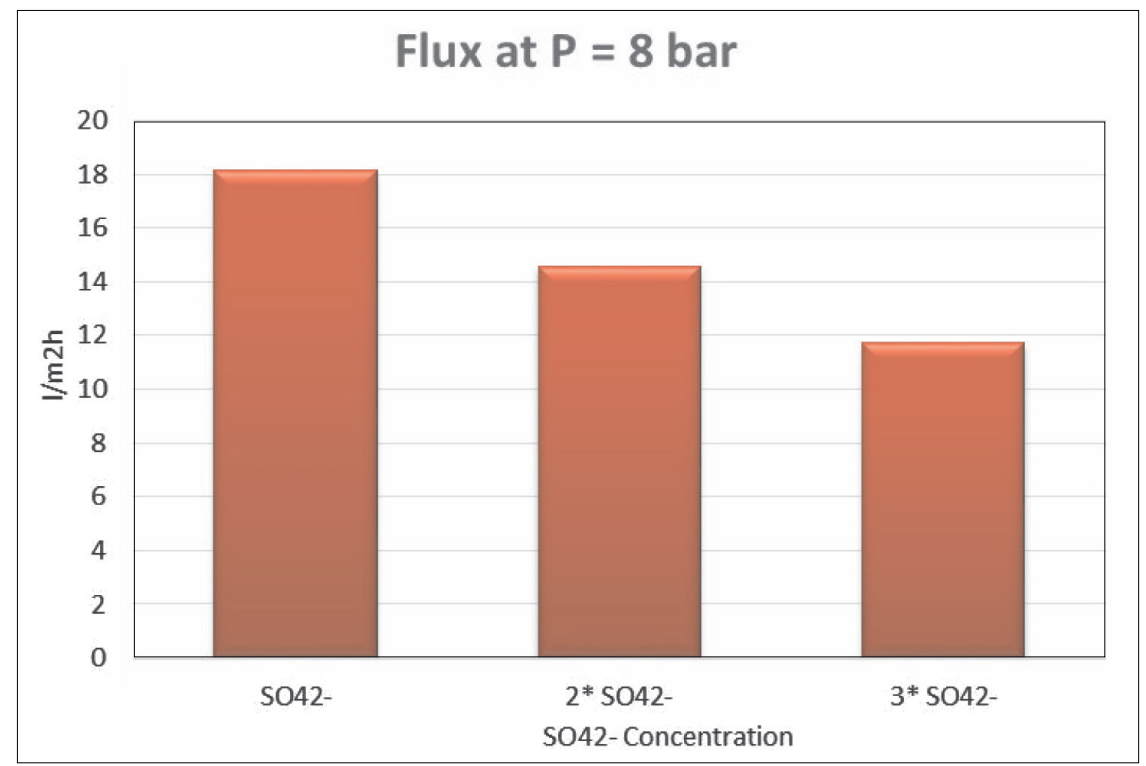

Fig. 7. Flux and $\mathrm{SO}_{4}{ }^{2-}$ 
Rejecting rates with increasing pressure is proportional for all ions except $\mathrm{SO}_{4}{ }^{2-}$. Larger ion size and the repulsive force from the negatively charged NF membrane result in high retention of $\mathrm{SO}_{4}{ }^{2-}$. Smaller ions and low hydration energy of $\mathrm{Na}^{+}$and $\mathrm{Cl}^{-}$compared to $\mathrm{SO}_{4}{ }^{2-}$ help monovalent ions to permeate more easily even at low pressure; i.e., diffusion controlled [11]. The retention of $\mathrm{Cl}^{-}$is low in order to satisfy the charge equilibrium requirements, balancing high permeation of counter ion $\mathrm{Na}^{+}$and high retention of co-ion $\mathrm{SO}_{4}{ }^{2-}$. The cations $\mathrm{Mg}^{2+}$ and $\mathrm{Ca}^{2+}$ are retained based on comparatively larger sizes and the charge balance in combination with retained $\mathrm{SO}_{4}{ }^{2-}$. However, the positive charge of the divalent cations creates a strong attractive force towards the negatively charged membrane and hence the retention is not as high as $\mathrm{SO}_{4}{ }^{2-}$ for $\mathrm{Mg}^{2+}$ and $\mathrm{Ca}^{2+}$.

Table 4

Permeate flow and rejection for 2 times $\mathrm{SO}_{4}{ }^{2-}$ spiking in seawater

\begin{tabular}{|c|c|c|c|c|c|}
\hline \multirow{2}{*}{$\begin{array}{c}\text { Permeate flow } \\
{[\mathrm{L} / \mathrm{h}]}\end{array}$} & Chloride & Sulphate & Sodium & Magnesium & Calcium \\
\cline { 2 - 6 } & 2.0 & 99.6 & 9.9 & 59.7 & 40.0 \\
\hline 80 & 2.2 & 99.8 & 11.7 & 65.8 & 44.5 \\
\hline 100 & 4.5 & 99.8 & 10.4 & 68.0 & 41.2 \\
\hline 115 & 3.9 & 99.8 & 11.1 & 66.4 & 39.1 \\
\hline 130 & 4.3 & 99.7 & 9.8 & 70.1 & 37.3 \\
\hline 145 & & & & & \\
\hline
\end{tabular}

Table 5

Permeate and rejection for 3 times $\mathrm{SO}_{4}{ }^{2-}$ spiking in normal seawater

\begin{tabular}{|c|c|c|c|c|c|}
\hline \multirow{2}{*}{$\begin{array}{c}\text { Permeate flow } \\
{[\mathrm{L} / \mathrm{h}]}\end{array}$} & \multicolumn{5}{|c|}{ Rejection [\%] } \\
\cline { 2 - 6 } & Chloride & Sulphate & Sodium & Magnesium & Calcium \\
\hline 80 & 4.0 & 99.7 & 19.7 & 57.1 & 28.3 \\
\hline 100 & 2.2 & 99.6 & 15.7 & 59.4 & 20.6 \\
\hline 115 & 5.9 & 99.6 & 18.4 & 60.9 & 25.2 \\
\hline 130 & 4.6 & 99.7 & 19.2 & 64.9 & 28.4 \\
\hline 145 & 2.2 & 99.5 & 19.8 & 53.2 & 24.9 \\
\hline
\end{tabular}

Rejection of $\mathrm{Ca}^{2+}$ ions is lower than for $\mathrm{Mg}^{2+}$ ions, which is due to a lower Stokes radius of $\mathrm{Ca}^{2+}$ as well as lower hydration energy (Tab. 1). $\mathrm{Ca}^{2+}$ also has higher affinity 
towards the membrane. The lower rejection of $\mathrm{Ca}^{2+}$ is also explained with the Donnan exclusion theory [2]. The negatively charged membrane will repel divalent anions such as $\mathrm{SO}_{4}{ }^{2-}$ and results in less retention of counter ions such as $\mathrm{Ca}^{2+}[5]$.

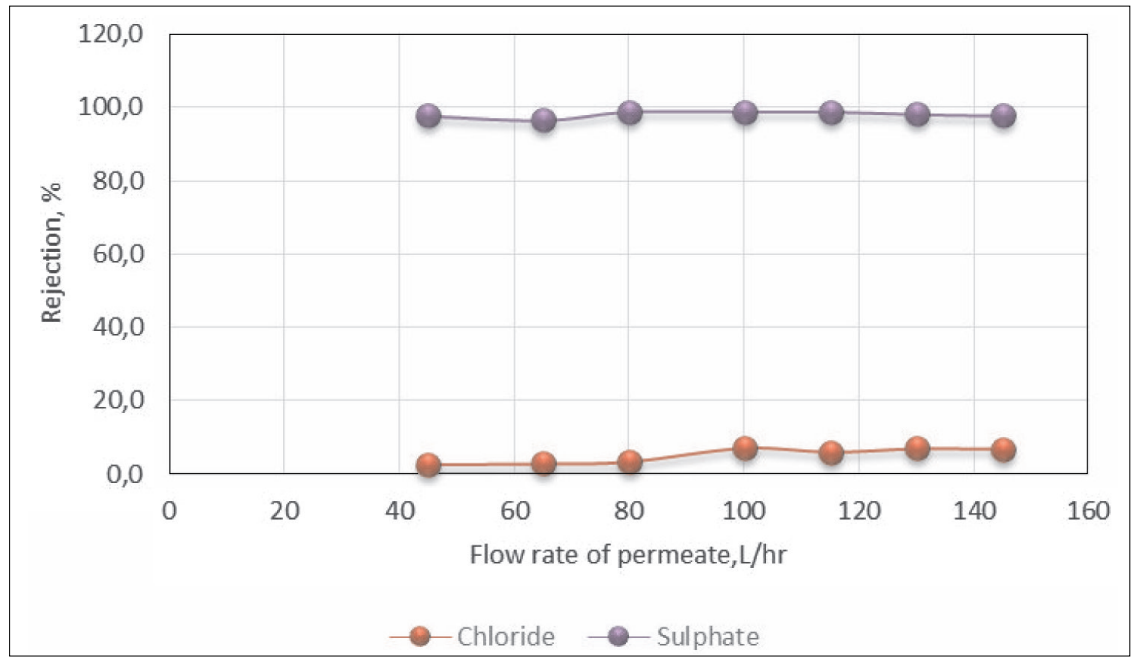

Fig. 8. Sulphate and chloride rejections

Rejection of divalent sulphate ions is high compared with monovalent chloride ions as seen in Figure 8. This is due to a number of factors, explained in Table $6[11,14]$.

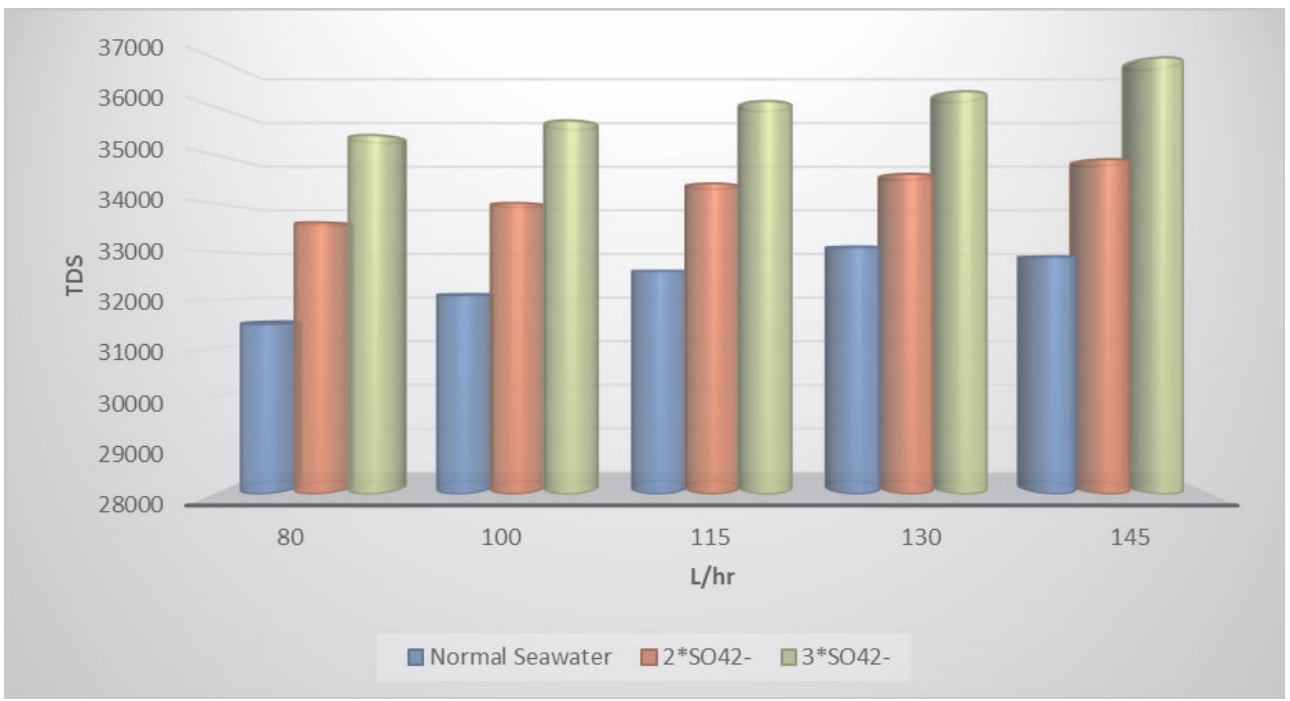

Fig. 9. Permeate and TDS of different $\mathrm{SO}_{4}{ }^{2-}$ concentrations 
Table 6

Parameters affecting sulphate and chloride retention

\begin{tabular}{|l|c|c|c|}
\hline \multicolumn{1}{|c|}{ Parameters } & Sulphate & Chloride & $\begin{array}{c}\text { Retention } \\
\text { Favors }\end{array}$ \\
\hline Stoke radius & High & Low & Sulphate \\
\hline Hydration energy & High & Low & Sulphate \\
\hline $\begin{array}{l}\text { Negatively charged } \\
\text { membrane affinity }\end{array}$ & Favourable & Favourable & Chloride \\
\hline Valency & High & Low & Sulphate \\
\hline
\end{tabular}

\section{EFFECT OF SPIKING}

The experiments show that there is high rejection of ions at lower feed concentrations and lower rejections at higher feed concentrations. This confirms that NF membrane separations are dependent on feed concentrations [12]. Figure 7 shows that the flux decreases as the concentration of $\mathrm{SO}_{4}{ }^{2-}$ in the feed increases at constant pressure, which is important from an economical point of view. The decrease in flux indicates an increase in resistance, which could be due to the effective membrane pore size reduction, concentration polarization or change in physical properties of the solution; i.e., density and viscosity.

Figure 9 shows that the TDS in retentate with normal seawater as feed, twice and thrice spiked with sulphate, was high for all cases. TDS in retentate increases with addition of $\mathrm{Na}_{2} \mathrm{SO}_{4}$ and is mainly due to the increase in feed TDS, high flux with loss of water to permeate.

\section{CONCLUSIONS}

Testing of NF membranes for production of Designer Water showed satisfying results in modifying ion composition of seawater. It is proven that Designer Water is produced from seawater by NF membranes. Retention of divalent ions in the retentate of NF makes retentate interesting for producing Designer Water. The rejections of salts increased with feed pressure and decreased with increasing feed concentrations. NF membrane is an exceptional contributor to production of designer water for IOR.

\section{REFERENCES}

[1] Abhang R.M., Wani K.S., Patil V.S., Pangarkar B.L., Parjane S.B.: Nanofiltration for recovery of heavy metal ions from waste water $-A$ review. International Journal of Research in Environmental Science and Technology, 3(1), 2013, $29-34$. 
[2] Ahmad A.L., Ooi B.S., Mohammad A.W., Choudhury, J.P.: Development of a highly hydrophilic nanofiltration membrane for desalination and water treatment. Desalination, 168, 2004, 215-221.

[3] Austad T.: Water Based EOR in Carbonates and Sandstones: New Chemical Understanding of the EOR-Potential Using 'Smart Water'. In: J. Sheng (ed.), Enhanced Oil Recovery Field Cases, 2012.

[4] Ayirala S.C., Yousef A.A.: Injection water chemistry requirement guidelines for IOR/EOR. In: SPE, Improved Oil Recovery Symposium, 12-16 April, 2014. Tulsa, Oklahoma, Society of Petroleum Engineers.

[5] Childress A., Elimelech M.: Effect of solution chemistry on the surface charge of polymeric reverse osmosis and nanofiltration membranes. Journal of Membrane Science, 119, (1996), 253-268.

[6] CRC for greenhouse gas technologies: $\mathrm{CO}_{2}$ capture/separation technologies. 2015 Retrieved from website: http://www.co2crc.com.au/aboutccs/cap_membranes.html.

[7] Fathi S.J., Austad T., Strand S.: Water-based Enhanced Oil Recovery (EOR) by 'Smart Water' in carbonate Reservoirs. In: SPE, EOR Conference at Oil and Gas West Asia, 2012, Muscat, Oman, Society of Petroleum Engineers.

[8] Gawaad R.S., Sharma S.K., Sambi S.S.: Comparative study of Nano and RO membrane for sodium sulphate recovery from industrial wastewater. ARPN Journal of Engineering and Applied Sciences, 6 (11), 2011.

[9] Hussain A.A., Abashar M.E.E., Al-Mutaz, I.S.: Effect of ion sizes on separation characteristics of nanofiltration membrane systems. Engineering Science, 9, 2006, 1-19.

[10] Kokal S.A., Al-Kaabi: Enhanced oil recovery: challenges and opportunities. World Petroleum Council, Official Publication, 2010.

[11] Krieg H.M., Modise S.J., Keizer K., Neomagus H.W.J.P.: Salt rejection in nanofiltration for single and binary salt mixtures in view of sulphate removal. Desalination, 171, 2004, 205-215.

[12] Peeters J.M.M., Boom J.P., Mulder M.H.V., Strathmann H.: Retention measurements of nanofiltration membranes with electrolyte solutions. Journal of Membrane Science, 145, 1998, 199-209.

[13] Richards L., Richards B.S., Corry B., Schafer A.I.: Response to Smith et al. 's comment on: Experimental energy barriers to anions transporting through nanofiltration membranes. Environmemntal Science Technology, 47(15), 2013, 8987-8988.

[14] Schaep J., Vandecastle C.: Evaluating the charge of nanofiltration membranes. Journal of Membrane Science, 188, 2001, 129-136

[15] Water Standard: Produced Water Management. 2012. Retrieved from website: http://waterstandard.com/technology. 